\title{
Unexpected Synthesis of Three Components from the Reaction of 4-Chloro-3-Formylcoumarin with Hydroxylamine Hydrochloride
}

\author{
AHMED ELKHATEEB ${ }^{1,2}$, ASHWAG S. ALSHEHRI ${ }^{1}$, \\ GILBERT KIRSCH ${ }^{3}$ and SH. H. ABDEL-HAFEZ ${ }^{1,4}$ \\ 'Department of Chemistry, Faculty of Science, Taif University, Taif 21974, Saudi Arabia. \\ 2Phytochemistry and Plant Systematic Department, \\ National Research Centre, Dokki, 12622 Giza, Egypt. \\ ${ }^{3}$ UMR 7565 SRSMC, Boulevard Arago, 57070 Metz, France. \\ ${ }^{4}$ Department of Chemistry, Faculty of Science, Assiut University, Assiut71516, Egypt. \\ ${ }^{*}$ Corresponding author E-mail: shams_abdelhafez@yahoo.com \\ http://dx.doi.org/10.13005/ojc/320142
}

(Received: November 03, 2015; Accepted: January 21, 2016)

\section{ABSTRACT}

\begin{abstract}
A mild and simple oximation reaction of 4-chloro-3-formylcoumarin with hydroxylamine hydrochloride in basic medium gave unexpected three components via oxime. Those compounds were separatedin good yields by preparative TLC and by chemical means using differentreaction conditions. IR, ${ }^{1} \mathrm{H}$ NMR, ${ }^{13} \mathrm{C}$ NMR and mass spectral data confirmed the structure of the separated compounds.
\end{abstract}

Key words: 4H-coumarin[3,4-d]isoxazol-4-one; ethyl-5-(2-hydroxyphenyl)-isoxazole-4 -formate; methyl-5-(2-hydroxyphenyl)-isoxazole-4-formate;4-chloro-3-cyano-coumarin.

\section{INTRODUCTION}

Derivatives of $4 \mathrm{H}-1$-benzopyran-4-one, also known as $4 \mathrm{H}$-chromen-4-ones or chromones, are an important scaffold in heterocyclic chemistry and represent useful synthetic building blocks in organic and medicinal chemistry'. Coumarins or Chromones are natural products possessing a wide range of valuable physiological activities ${ }^{2}$. From literature survey the syntheses of 2-aminochromone-3carboxamide, 3-amino-4H-chromeno[3,4-d]isoxazol- 4-one, and 3-(diaminomethylene) chroman-2,4-dione were developed ${ }^{3}$ from the reactions of 3-substituted chromones (3-formylchromone, 3-formylchromone3-oxime, and 3-cyanochromone) with hydroxylamine in alkaline medium.3-Formylchromones when treated with hydroxylamineformed via 3-formylchromoneoximes 3-cyanochromones ${ }^{4,5}$. The ability of 3-cyanochromones to interact with water followed by pyrone ring opening and cyclizationat the $\mathrm{CN}$ group formed 2-amino-3-formylchromone ${ }^{5,6}$. 
In this study we have investigatedthe reaction of 4-chloro-3-formylcoumarin with hydroxylamine hydrochlorideatdifferent conditions to see if the reaction will have the same behavior as previouslydescribed in literature ${ }^{3}$.

\section{RESULTS AND DISCUSSION}

The literature survey revealed some debate about the assignment of the structure of the reaction products of coumarin derivatives with hydroxylamine.

Among these investigations,Sosnovskikhet al. in $2008^{3}$ studied the reactions of chromones 1-3with hydroxylamine hydrochloride in strongly basic medium to give 3-amino-4H-chromeno[3,4-d] isoxazol-4-one $\mathbf{4}$ which was converted into acid $\mathbf{5}$ when heated in $10 \%$ boiling sodium hydroxide.

Furtherrecyclization and reduction of compound 4led to the formation of 3-(diaminomethylene) chroman-2,4-dione 6.

Therefore, westudied the reaction of 4-chloro-3-formylcoumarin8 instead of compounds 1-3 with hydroxylamine under different conditions. We identifiedthree unexpected compounds; 4-chloro-3cyano-coumarin (10); 4H-chromeno[3,4-d]isoxazol4-one (11); Ethyl-5-(2-hydroxyphenyl)-isoxazole4-formate (12a); (or methyl-5-(2-hydroxyphenyl)-<smiles>[X]c1coc2ccccc2c1=O</smiles>

1-3 $\mathrm{X}=\mathrm{CHO}, \mathrm{CH}=\mathrm{NOH}, \mathrm{CN}$ isoxazole-4-formate (12b)(depending on the solvent) formed through oxime(9) (Scheme 1).

These 3 compounds were prepared as follow: 1equivalent of starting compound $\mathbf{8}$ with 1eq. of hydroxylamine hydrochloride in the presence of 1eq. of sodium acetate as a basic medium were refluxed for $4 \mathrm{hrs}$. Formation of compounds 1012 was monitored by TLC and GC/MS. When the reaction was carried out by using 3eq hydroxylamine/ 3eq sodium acetate in ethanol and was refluxed for 10 hrs.purecompound 11 was isolated and the structure confirmed on the basis of IR, 'HNMR, ${ }^{13} \mathrm{CNMR}$ and mass spectra.A characteristic singlet peak at ä 10.21 due to $\mathrm{CH}$-isoxazole moiety was present in ${ }^{1} \mathrm{HNMR}$. Treatment of chromones 8(1eq) with 3 eq of hydroxylamine and 3eq of sodium acetate under reflux 24hrs.gavepure12 a in ethanol or $12 \mathrm{~b}$ in methanol(Scheme 2).

Structures of $12 \mathrm{a}$ and $12 \mathrm{~b}$ were confirmed on the basis of spectral analysis.Compound 10 was obtained directly when the reaction was carried out under stirring 5 minutes by using $3 \mathrm{eq}$ hydroxylamine/3eq sodium acetate in ethanol as a solvent (Scheme 3).

It was found that the spectral data of 10 were in agreement with literature results [7](m.p.199$200^{\circ} \mathrm{C}$ ). These compounds $10-12$ were separated and purified by chromatographyusinghexane/ethyl acetate (8:2) as eluent.

Concerning the mechanism 10 was formed by elimination of water from oxime (9); 11 was formed by elimination of $\mathrm{HCl}$ to ring closure. Finally, the ethylesterisoxazole12a was obtained via ring opening of coumarin (lactone)by the action of ethanol.

In order to study the effect of solvent, we have repeated the reaction in methanol instead of ethanol to give methylesterisoxazole $12 \mathrm{~b}$ (Scheme2).<smiles>Nc1noc2c1c(=O)oc1ccccc12</smiles>

4<smiles>Nc1noc(-c2ccccc2O)c1C(=O)O</smiles>

5<smiles>NC(N)=C1C(=O)Oc2ccccc2C1=O</smiles>

6 
A possible route for the multi-step mechanism is outlined in (Scheme 4).

We suggest that the hydroxylamine in basic medium converts 8 into the key intermediate compound $\mathbf{9}$ which then undergoes further recyclizationby eliminationof $\mathrm{HClto}$ afford coumarino[3,4-d]isoxazole11. Ethanol or methanol makes the ring opening of the lactone part to form compounds $12 \mathrm{a}, \mathrm{b}$.

In conclusion, the starting compound 4-chloro-3-formyl coumarin 8 showed different reactivity depending on the reaction conditions. Its reaction with hydroxylamine gives a variety of products. The obtained products were $4 \mathrm{H}$ coumarino[3,4-d]isoxazol-4-one; ethyl-5-(2hydroxyphenyl)-isoxazole-4-formate or methyl5-(2-hydroxyphenyl)-isoxazole-4-formate) and 4-chloro-3-cyano-coumarin.

\section{Experimental Section} General Procedures.

Melting points were determined by using the Kofler melting point apparatus, and were uncorrected. IR $\left(\mathrm{KBr}, \mathrm{cm}^{-1}\right)$ spectra were recorded on a Pye-Unicam SP3-100 instrument at Taif University. ${ }^{1} \mathrm{H}$ NMR spectra were obtained on a Varian (400 $\mathrm{MHz})$ EM 390 USA instrument at King Abdel-Aziz University. ${ }^{13} \mathrm{C}$ NMR spectra were recorded on a JNM-LA spectrometer $(100 \mathrm{MHz})$ at King AbdelAziz University, Saudi Arabia. For both ${ }^{1} \mathrm{H}$ and ${ }^{13} \mathrm{C}$ -NMR, DMSO $d_{6}$ was used. Spectra were internally referenced to TMS. Peaks are reported in ppm downfield of TMS. Multiplicities are reported as singlet (s), doublet (d), triplet (t), quartet (q).

Mass spectra were recorded on ISQThermo Scientific GC-MS. GC column TG-SQC, Trace GC ultra at TaifUniversityKSA.Purity of the compounds
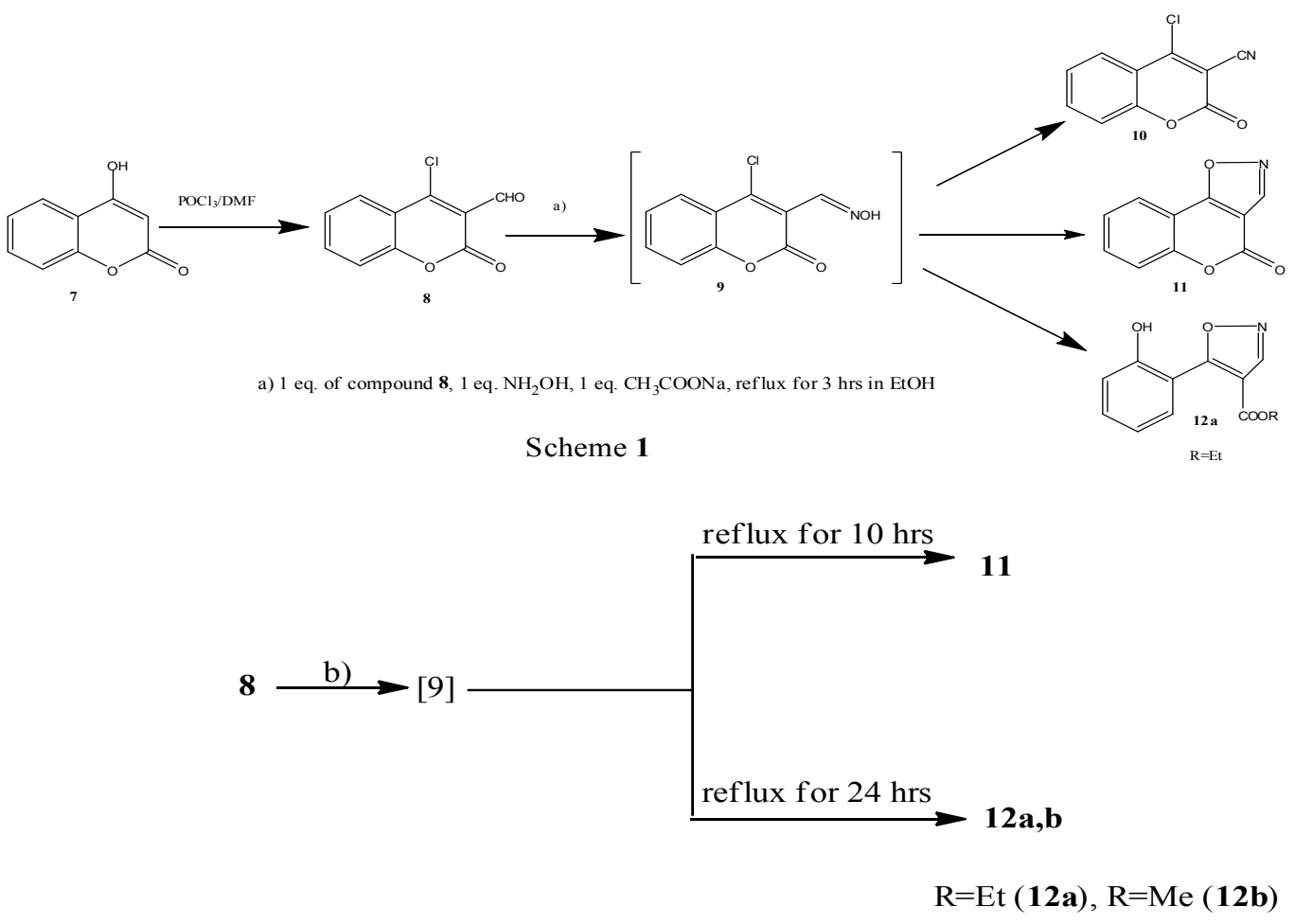

b) 1 eq. of compound $\mathbf{8}, 3$ eq. $\mathrm{NH}_{2} \mathrm{OH}, 3$ eq. $\mathrm{CH}_{3} \mathrm{COONa}$, in $\mathrm{EtOH}(\mathbf{1 2 a}), \mathrm{MeOH}(\mathbf{1 2 b})$

Scheme 2 
was checked by thin layer chromatography (TLC) using silica gel plates.Column chromatography was carried out on $0.04 " 0.063 \mathrm{~mm}$ (Merck) silica gel, thin layer chromatography was carried out on aluminum backed silica plates by Merck and plates were revealed using a UV 254 light.

\section{MATERIALS}

The 4-hydroxycoumarin 7 was a gift from the Lab of Prof. Gilbert Kirsch, Laboratoired'Inge'nierieMole'c ulaire et BiochimiePharmacologique, Institut Jean Barriol, FR Metz, France..

\section{4-Chloro-3-coumarincarbaldehyde (8)}

Compound 8 was prepared as previously describe by sabitaeet.al with a little bit modification $^{8}$.
To a stirred mixture of 4-hydroxycoumarin 7 (9.72 g, 0.06mol) in anhydrous DMF $(46.2 \mathrm{~mL}$, $0.6 \mathrm{~mol}$ ) were added dropwise $\mathrm{POCl} 3$ (27.6 g, 0.18 mol) at $-10^{\circ}$ to $-5{ }^{\circ} \mathrm{C}$. The reaction mixture was then stirred for $1 \mathrm{hr}$ at room temperature after that heated and stirred for $5 \mathrm{hrs}$.at $80{ }^{\circ} \mathrm{C}$. The reaction mixture was poured onto crushed ice $(300 \mathrm{~g})$ under vigorous stirring. The reaction mixture was kept overnight at $0^{\circ} \mathrm{C}$. The pale yellow solid was collected by filtrationand recrystallized from acetone to give $10.5 \mathrm{~g}(84 \%)$ of 8 ; m.p. $133-135^{\circ} \mathrm{C}\left(\text { lit. } 130{ }^{\circ} \mathrm{C}\right)^{9}$

1H-NMR $\delta 10.39(1 \mathrm{H}, \mathrm{s}, \mathrm{CH}=\mathrm{O}), 8.16-7.28$ (4H, m, Ar-H); IR í 1720 (C=O-pyrone), 1663 (CHO) $\mathrm{cm}^{-1}$. El-MS m/z: 208 (M+, 11), 182 (31), 180 (100), 154 (31), 152 (91), 124 (20), 101 (11), 89 (80), 63 (37), 62 (31), 61 (14); El-HRMS: m/z 207.9909 (calculated for $\mathrm{C}_{10} \mathrm{H}_{5} \mathrm{ClO}_{3} 207.9927$ )

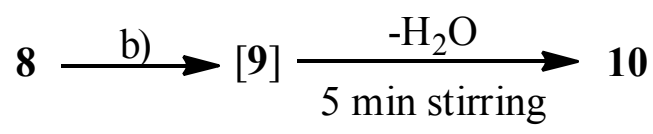

b) 1 eq. of compound $\mathbf{8}, 3$ eq. $\mathrm{NH}_{2} \mathrm{OH}, 3$ eq. $\mathrm{CH}_{3} \mathrm{COONa}$, in $\mathrm{EtOH}$

\section{Scheme 3}

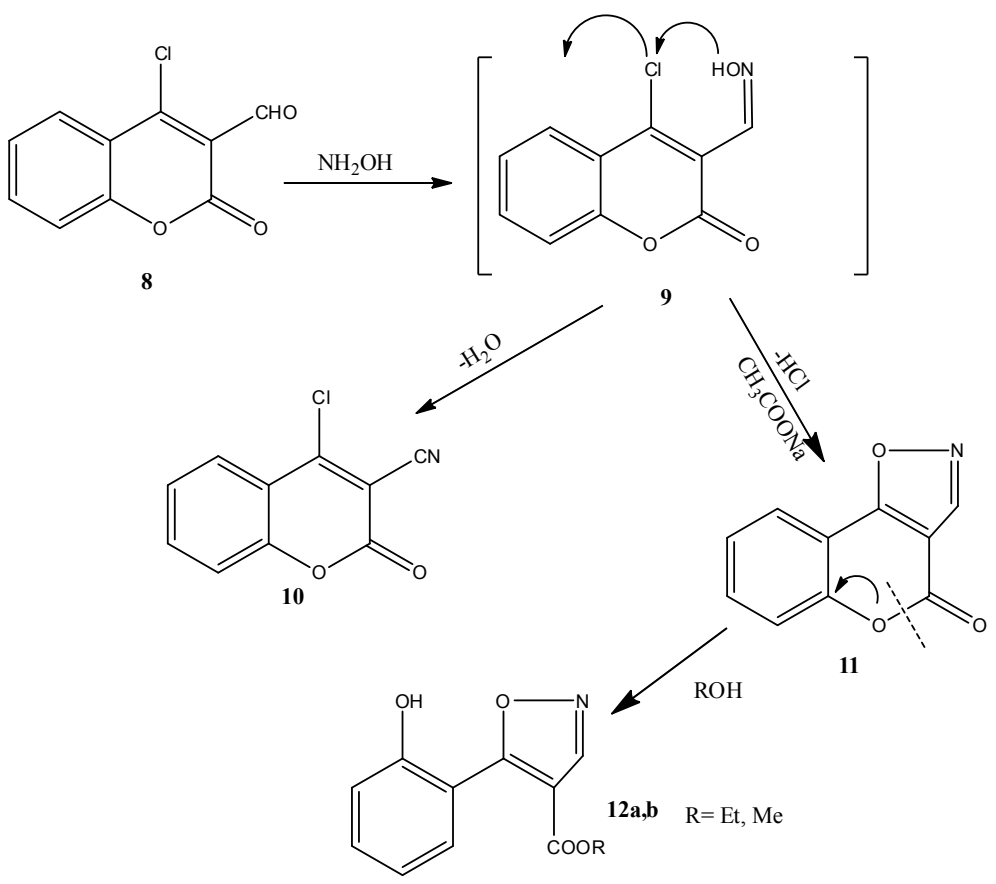

Scheme 4 
3-Cyano-4-chlorocoumarin (10), 4H-chromeno [3,4-d]isoxazol-4-one (11), ethyl 5-(2hydroxyphenyl)isoxazole-4-carboxylate (12a) and Methyl-5-(2-hydroxyphenyl)-isoxazole-4formate (12b)

\section{General procedure}

To a mixture of $\mathrm{NH}_{2} \mathrm{OH} . \mathrm{HCl}$ (1 eq.) and anhydrous sodium acetate ( 1 eq.)in ethanol, or methanol a solution of compound 8 ( 1 eq.) in ethanol was added. The reaction mixture was refluxed for $3 \mathrm{hrs}$. After the reaction completed, the reaction mixture was poured onto crushed ice $(300 \mathrm{~g})$ under vigorous stirring. The pale yellow solid was collected by filtration and further purified by silica gel column chromatography using a mixture of hexane/ethyl acetate $(8: 2)$ as eluent to afford the desired three compounds10, 11 and 12a,b.

\section{Notes}

Compound 10 was prepared by using 3eq of $\mathrm{NH}_{2} \mathrm{OH} . \mathrm{HCl} / 3$ eq anhydrous sodium acetate and 1 eq of compound 8 in ethanol. The reaction mixture was stirred for 5 minute to give compound 10 as yellow crystal m.p. $198-200^{\circ} \mathrm{C}$ (Lit, $\left.199-200^{\circ} \mathrm{C}\right)^{9}$

\section{H-Chromeno [3,4-d]isoxazol-4-one (11)}

m.p. $222-224{ }^{\circ} \mathrm{C} ;{ }^{\mathrm{H}} \mathrm{H}-\mathrm{NMR} \delta 10.21(1 \mathrm{H}, \mathrm{s}$, $\mathrm{CH}$-isoxazole), 8.03-7.41 (4H, m, Ar-H); ${ }^{13} \mathrm{C}-\mathrm{NMR}$ ä 165.50, 155.04, 154.90, 152.80, 133.36, 125.29, 124.07, 117.67, 110.24, 107.83. IR í 1761 (C=Opyrone), $1608(\mathrm{C}=\mathrm{N}) \mathrm{cm}^{-1}$. El-MS m/z: $187(\mathrm{M}+$, 100), 159 (33), 131 (11), 119(4), 103 (54), 76 (26). El-HRMS: $\mathrm{m} / \mathrm{z} 187.0268$ (calculated for $\mathrm{C}_{10} \mathrm{H}_{5} \mathrm{NO}_{3}$ : 187.0269)

\section{Ethyl-5-(2-hydroxyphenyl)-isoxazole-4-formate} (12a)

m.p. 218-220 ${ }^{\circ} \mathrm{C} ;{ }^{1} \mathrm{H}-\mathrm{NMR}\left(\mathrm{CDCl}_{3}\right) \delta 9.02(1 \mathrm{H}$, $\mathrm{s}, \mathrm{CH}$-isoxazole), 8.12-7.01 (4H, m, Ar-H), $4.37(2 \mathrm{H}$, $\left.\mathrm{q}, \mathrm{J}=6.80 \mathrm{~Hz}, \mathrm{CH}_{2}\right) ; 1.36\left(3 \mathrm{H}, \mathrm{t}, \mathrm{J}=6.80 \mathrm{~Hz}, \mathrm{CH}_{3}\right) .{ }^{13} \mathrm{C}-$ NMR ä 175.80, 163.49, 160.60, 155.68, 134.01, $125.66,122.80,118.68,116.20 .93 .54,60.29,13.72$. IR í 1669 (C=O...H-bond), $1601(\mathrm{C}=\mathrm{N}) \mathrm{cm}^{-1}$. El-MS $\mathrm{m} / \mathrm{z} 233$ (M+, 33), 187 (100), 159 (41), 131 (12), 119 (4), 103 (35), 76 (8); El-HRMS:m/z 233.0684 (calculated for $\mathrm{C}_{12} \mathrm{H}_{11} \mathrm{NO}_{4}:$ : 233.0688)

\section{Methyl 5-(2-hydroxyphenyl)isoxazole-4-} carboxylate (12b)

m.p. $210-212^{\circ} \mathrm{C} ;{ }^{1} \mathrm{H}-\mathrm{NMR}\left(\mathrm{CDCl}_{3}\right) \delta 9.02$ (1H, s, CH-isoxazole), 8.12-7.01 $(4 \mathrm{H}, \mathrm{m}, \mathrm{Ar}-\mathrm{H})$, $3.91\left(3 \mathrm{H}, \mathrm{s}, \mathrm{OCH}_{3}\right) . \mathrm{IR} v 1670(\mathrm{C}=\mathrm{O} \ldots \mathrm{H}$-bond $), 1600$ $(\mathrm{C}=\mathrm{N}) \mathrm{cm}^{-1}$. El-MS m/z219 (M+, 49), 187 (100), 159 (34), 131 (15), 119 (4), 103 (99), 76 (40). El-HRMS: $\mathrm{m} / \mathrm{z} 219.0492$ (calculated for $\mathrm{C}_{11} \mathrm{H}_{9} \mathrm{NO}_{4}:$ 219.0532).

\section{REFERENCES}

1. (a) Nohara, A.; Kuriki, H.; Saijo, T.; Sugihara, H.; Kanno, M.; Sanno, Y. J. Med. Chem.1977, 20, 141-145; (b) Nohara, A.; Umetani, T.; Ukawa, K.; Sanno, Y. Chem. Pharm. Bull. 1974, 22, 2959-2965; (c) Ukawa, K.; Ishiguro, T.; Wada, Y.; Nohara, A. Heterocycl.,1986, 24, 1931-1941; (d) Hsung, R. P. J. Org. Chem. 1997, 62, 7904-7905; (e) Hsung, R. P.; Zificsak, C. A.; Wei, L.-L.; Zehnder, L. R.; Park, F.;Kim, M.; Tran, T.-T. T. J. Org. Chem. 1999, 64, 8736-8740; (f)

Sosnovskikh, V.Ya.;Irgashev, R. A.; Levchenko, A. A. Tetrahedron,2008, 64, 6607-6614.

2. Horton, D. A.; Bourne, G. T.; Smythe, M. L. Chem. Rev. 2003, 103, 893-930.

3. VyacheslavYa. Sosnovskikh, Vladimir S.
Moshkin, Mikhail I. Kodess

Tetrahedron Lett.,2008,49, 6856-6859

4. (a) Nohara, A. Tetrahedron Lett.1974, 1187-1190; (b) Klutchko, S.; Cohen, M. P.; Shavel, J.; von Strandtmann, M. J. Heterocycl. Chem.1974, 11, 183-188.

5. (a) Petersen, U.; Heitzer, H. Liebigs Ann. Chem. 1976, 1659-1662; (b) Hagen, H.; Nilz, G.; Walter, H.; Landes, A.; Freund, W. DE Patent 4039281, 1992; Chem. Abstr.1992, $117,111473 \mathrm{k}$.

6. Nohara, A.; Ishiguro, T.; Ukawa, K.; Sugihara, H.; Maki, Y.; Sanno, Y. J. Med. Chem.1985, 28, 559-568.

7. Stojadin V. Dekiæ1, Vidoslav S. Dekiæ1, Branimirka Vuèiæ2, Biljana R. Dekiæ1, Milan S. 
8. Dekiæ3. Physics, Chemistry and Technology,2007, 5 (1) 85 - 88; Sabatie A., Vegh D., Floch L',Arkivoc,2001 (vi) 122-128
Andrieux J., Battioni, J.P., Giraud M., Molho D., Bull.Soc. Chem. Fr.1973,6,2093 